\title{
Metabolic syndrome in men and women with upper or lower types of body fat distribution
}

\author{
Boris B. Pinkhasov*, Vera G. Selyatitskaya, Ani R. Karapetyan, Elvira L. Astrakhantseva
}

Siberian Branch of Russian Academy Medical Sciences, Scientific Centre of Clinical and Experimental Medicine, Novosibirsk, Russia; ${ }^{*}$ Corresponding Author: pin@,soramn.ru, pin71nsk@mail.ru

Received 11 November 2012; revised 15 December 2012; accepted 24 December 2012

\section{ABSTRACT}

The purpose of the study was to determine the prevalence of metabolic syndrome as a cluster of risk factors for atherosclerotic cardiovascular disease and type 2 diabetes mellitus and its individual components in groups of men and women with primary obesity having different types of fat distribution. The study involved 142 men and 185 women with primary alimentary-constitutional obesity. The study participants were divided into 2 groups depending on waist-to-hip ratio value. Standardized criteria were used to determine the prevalence of metabolic syndrome and its individual components among the examined men and women. The ratios of the number of participants with lower or upper type of fat distribution in men and women were 28:114 and $84: 101$, respectively. Hence the frequency of lower type of fat distribution was $19.7 \%$ in men and $45.4 \%$ in women $(p<0.000)$. Men with lower type of body fat distribution as compared to upper type were characterized by a lower prevalence of abdominal obesity (1.9 times), hypertriglyceridemia (1.4 times), low HDL-C (1.6 times), and hypertension (2 times). The frequency of metabolic syndrome in men with lower type of fat distribution was lower by 2.7 times than that of men with upper type of fat distribution. Women with lower type of fat distribution as compared to upper type had a lower prevalence of abdominal obesity (1.2 times), hypertriglyceridemia (1.8 times), low HDL-C (1.2-fold), and hypertension (in 1.5 times). The frequency of metabolic syndrome in women with lower type of fat distribution was lower by $\mathbf{1 . 9}$ times than that of women with upper type of fat distribution. Both men and women in the groups with lower type of fat distribution were missing such a component of metabolic syndrome as hyperglycemia i.e. they had the minimal risk of type 2 diabetes mellitus.

Keywords: Metabolic Syndrome; Obesity; Fat Distribution

\section{INTRODUCTION}

Metabolic syndrome (MS) presents the cluster of risk factors for atherosclerotic cardiovascular disease and type 2 diabetes mellitus, the major causes of mortality in industrialized countries [1-4]. In this context, much attention is devoted to identifying MS prevalence in people of different gender, age, social groups and among individuals with cardiovascular and/or other diseases, etc. [5-7]. These risk factors include raised blood pressure, dyslipidemia (raised triglycerides and lowered high-density lipoprotein cholesterol), raised fasting glucose and central obesity [4].

Insulin resistance has been proposed as the key linking factor for the MS disease. The combination of insulin resistance and compensatory hyperinsulinemia increases the likelihood that an individual will be hypertensive, and have a dyslipidemia characterized by a high plasma triglyceride and low high-density lipoprotein cholesterol concentration. These changes increase risk of cardiovascular disease, and in 1988, this cluster of related abnormalities was designated as comprising a syndrome (X). Several other clinical syndromes are now known to be associated with insulin resistance and compensatory hyperinsulinemia. For example, polycystic ovary syndrome appears to be secondary to insulin resistance and compensatory hyperinsulinemia. More recently, studies have shown that the prevalence of insulin resistance/hyperinsulinemia is increased in patients with nonalcoholic fatty liver disease, and there are reports that certain forms of cancer are more likely to occur in insulin resistant/hyperinsulinemic persons [8].

Most of the epidemiological, experimental, and clinical evidence support the role of hyperinsulinemia and insulin resistance as important components of this multifaceted syndrome. However, there is evidence amassing 
that a neurohormonal mechanism, including an endocrine role for adipocytes, also plays a fundamental role [9]. There are data suggesting that hyperleptinemia rather than, or synergistically with hyperinsulinemia, may play some role in the genesis of the MS. More recently, other potential players in the etiology of the MS have been suggested including endothelial dysfunction and acetylation-stimulating protein [10].

Two of the proposed systems of MS criteria are actively used today. The first one was developed by experts of the International Diabetes Federation (IDF) [11], and the second one was developed by experts of the National Cholesterol Education Program Adult Treatment Panel III (NCEP-ATP III) [12]. The key difference of these systems of MS indices are the boundary values of such a criterion as abdominal obesity (AO) and the condition of its presence as an obligatory MS component in the system of IDF criteria. Comparative studies of MS prevalence depending on the applied criteria were conducted, and, taking into account that the boundary values of waist circumference for the identification of abdominal obesity presented as IDF criteria are lower than those presented as NCEP-ATP III criteria, MS incidence rates were higher in the first case [13-16]. In 2009, unified MS criteria representing the outcome of a meeting between several major organizations were published [4]. It was agreed, that there should not be an obligatory component, and a single set of cut points would be used for all components except waist circumference. This is due to variability of waist circumference in several different populations and ethnic groups [4].

The regional body fat distribution is a significant risk factor for developing type 2 diabetes mellitus and hypertension. The ratio of waist circumference to hip circumference (waist-to-hip ratio, WHR) $[17,18]$ is one of the indices characterizing body fat distribution. WHR value is of great interest for obesity specialists since the use of this index allows us to divide obese individuals into groups with upper (android) and lower (gynoid) types of body fat distribution. The distinction between individuals with the android and the gynoid types of obesity by calculating the brachio-femoral adipo-muscular ratio was proposed Vague J. [19], who substantiated the association of the android (upper) type of obesity with a high risk of cardiovascular disease and type 2 diabetes mellitus. Then it was suggested to distinguish the central and peripheral obesity or upper and lower obesity based on WHR $[20,21]$. In recent years, the dual-energy X-ray absorptiometry and computed tomography scans were used to identify the regional fat distribution $[22,23]$; however, these are expensive methods that are not suitable for mass screening. The method, which lends itself easily to largescale screening studies, involves the determination of the WHR. As comparative studies show, it is the WHR, ra- ther than the body mass index or waist circumference, that is the most useful measure of obesity to use for identifying individuals with cardiovascular disease risk factors [24-26].

The upper type of fat distribution is associated with intra-abdominal visceral fat accumulation, which plays an important role in the development of diabetes, lipid disorder, hypertension and atherosclerosis [27]. Visceral fat cells have a much greater metabolic activity as compared to subcutaneous fat cells. They also differ in their ability to secrete adipokines [28,29]. Visceral adipose tissue and its adipose-tissue resident macrophages produce more proinflammatory cytokines like tumor necrosis factor-alpha and interleukin-6 and less adiponectin. These cytokines changes induce insulin resistance and play a major role in the pathogenesis of endothelial dysfunction and subsequent atherosclerosis [30]. Accumulation of visceral fat at abdominal obesity substantiates its role as one of the main MS components [31,32].

At the lower type of fat distribution accompanied by its accumulation in the gluteofemoral area, subcutaneous fat far outweighs the metabolic disorders associated with abdominal obesity $[30,33,34]$. Therefore, upper and lower types of fat distribution should be associated with different degrees of the risk of cardiovascular and metabolic disorders. The association of high risk of their development with upper type of body fat distribution was convincingly demonstrated [27-31]. However, the degree of association of lower type of fat distribution in women with cardiovascular and metabolic disorders is not well known. It is important because the frequency of lower type fat distribution reaches $40 \%-50 \%$ in women of reproductive age who are overweight and have primary obesity [35].

In the study of gender-specific peculiarities of obesity, men are almost entirely classified under the group with upper type of fat distribution [36], though the practice of obesity correction indicates that it is not quite correct. The prevalence of lower type of fat distribution in obese men is practically not discussed in literature. Comparative studies of fat distribution types association with MS apply only to women [37]. Hence, the purpose of the study was to determine the prevalence of MS as a cluster of risk factors for atherosclerotic cardiovascular disease and type 2 diabetes mellitus and its individual components in groups of men and women with primary obesity having different types of fat distribution.

\section{METHODS}

\subsection{Subjects}

The study involved 142 men and 185 women aged 21 to 70 years $(\mathrm{M} \pm \mathrm{SD}$ age of $45.0 \pm 10.4$ years). The inclusion criterion for selecting participants for this re- 
search was presence primary alimentary-constitutional obesity with body mass index equal to or higher than 30 $\mathrm{kg} / \mathrm{m}^{2}$. The exclusion criteria were morbid and neuroendocrine obesity, diabetes mellitus 1 and 2 types, acute heart and pulmonary diseases, malignancy, acute infections and inflammatory diseases. The work was conducted at the Clinical Research and Practical Center of Correction of Endocrine and Metabolic Disorders. All patients involved in the study gave their informed consent to participate in the investigation, which complied with the ethical standards developed in accordance with the World Medical Association Declaration of Helsinki on Ethical Principles for Medical Research Involving $\mathrm{Hu}-$ man Subjects, and a permit was obtained from the Local Biomedical Ethics Committee.

\subsection{Instrumentation and Measures}

Anthropometric measurements including height, body weight, waist and hip circumferences were obtained using standardized procedures. Body weight was measured using medical balance to the nearest $100 \mathrm{gm}$, height with the help of stadiometer to the nearest $5 \mathrm{~mm}$. Waist circumference $(\mathrm{cm})$ and hip circumference $(\mathrm{cm})$ were determined using measuring tape to the nearest $5 \mathrm{~mm}$ as described in the WHO Guidance (2008) [38]. Blood pressure measured using machinal pulsometer UA-100, A\&D, Japan.

A 12-hour fasting blood sample was draw from each participant in the morning. The concentration of lowered high-density lipoprotein cholesterol (HDL-C) in blood serum was assayed with the enzymatic colorimetric peroxidase (POD) method and the concentration of triglycerides in blood serum was assayed with the enzymatic colorimetric test using analyzer "Konelab 30i" Thermo Electron Corporation, Finland. The concentration of blood glucose was assayed with the glucose oxidase test (spectrophotometric method) at the "Photometer 5010", Boehringer Mannheim, Germany.

Body mass index was calculated as weight divided by height squared $\left(\mathrm{kg} / \mathrm{m}^{2}\right)$. Waist-to-hip ratio was calculated by dividing waist circumference by hip circumference. The study participants were divided into 2 groups depending on WHR value. When this value was less than 0.95 for men and less than 0.85 for women, these individuals were classified under groups with lower type of fat distribution, and when this value was 0.95 and higher for men and 0.85 and higher for women, they were classified under the group with upper type of fat distribution.

\subsection{Metabolic Syndrome}

Standardized criteria were used to determine the prevalence of MS and its individual components among the examined men and women [4]. The values of waist cir- cumference $\geq 102 \mathrm{~cm}$ for men and $\geq 88 \mathrm{~cm}$ for women were used to diagnose abdominal obesity. Categorical cut points for revelation of hypertriglyceridemia (elevated triglycerides $\geq 1.7 \mathrm{mmol} / \mathrm{L}$ or drug treatment for elevated triglycerides is an alternate indicator), reduced HDL-C (HDL-C $<1.0 \mathrm{mmol} / \mathrm{L}$ in men and HDL-C $<1.3$ $\mathrm{mmol} / \mathrm{L}$ in women, or drug treatment for reduced HDL-C is an alternate indicator), elevated blood pressure (systolic $\geq 130$ and/or diastolic $\geq 85 \mathrm{~mm} \mathrm{Hg}$, or antihypertensive drug treatment in a patient with a history of hypertension is an alternate indicator ), elevated fasting glucose (blood glucose $\geq 5.6 \mathrm{mmol} / \mathrm{L}$, or drug treatment of elevated glucose is an alternate indicator) are the same for men and women according to modern ideas [4]. Metabolic syndrome was diagnosed when at least three of any of its components were present.

\subsection{Statistical Analysis}

Statistical data processing was performed using the Statistica 6.0 program (StatSoft, USA). In Tables 2 and 4 , the results are presented as incidence in \%, the comparative analysis was performed using the Pearson's $\chi^{2}$ test (for two groups with Yates correction). In the text, Tables 1 and 3, the results are presented as mean indicator values and the standard deviation $(\mathrm{M} \pm \mathrm{SD})$; the comparative analysis was performed using the Mann-Whitney test for paired comparisons. The coefficient of variation was calculated in $\%$ as the ratio of the standard deviation to the mean value multiplied by 100 . The minimum probability of the null hypothesis validity was accepted at the $5 \%$ significance level $(\mathrm{p}<0.05)$.

\section{RESULTS}

Table 1 presents the results of measuring the anthropometric and metabolic indices of the examined men and women with alimentary-constitutional obesity depending on the gender. No differences were observed in the mean values of age and body mass index, while all the other indices differed between groups of men and women with a high degree of reliability.

Table 2 presents the results of determining the prevalence of metabolic syndrome and its individual components in the examined men and women with alimentaryconstitutional obesity.

Abdominal obesity prevalence ranked first in men and women. Hypertriglyceridemia and hypertension ranked second in men, and hypertension ranked second in women with approximately equal prevalence. Low level of HDL cholesterol ranked third in both men and women, followed by hypertriglyceridemia in women due to its decreasing prevalence. Hyperglycemia was the last by its prevalence in both men and women. Due to the significantly lower prevalence of hypertriglyceridemia, hyper- 
Table 1. Baseline characteristics of obese male and female.

\begin{tabular}{cccc}
\hline Variable & $\begin{array}{c}\text { Men }(\mathrm{N}=142) \\
\mathrm{M} \pm \mathrm{SD}\end{array}$ & $\begin{array}{c}\text { Women }(\mathrm{N}=185) \\
\mathrm{M} \pm \mathrm{SD}\end{array}$ & p value \\
\hline Age (years) & $45.3 \pm 10.1$ & $44.7 \pm 12.4$ & 0.436 \\
Weight $(\mathrm{kg})$ & $110.8 \pm 19.7$ & $94.0 \pm 16.2$ & $0.000^{*}$ \\
Height (cm) & $177.1 \pm 6.2$ & $161.9 \pm 6.1$ & $0.000^{*}$ \\
BMI & $35.2 \pm 5.2$ & $35.8 \pm 5.4$ & 0.227 \\
Waist circumference (cm) & $113.3 \pm 12.1$ & $100.5 \pm 10.7$ & $0.000^{*}$ \\
Hip circumference (cm) & $113.6 \pm 10.1$ & $117.8 \pm 10.7$ & $0.000^{*}$ \\
WHR & $1.00 \pm 0.06$ & $0.85 \pm 0.07$ & $0.000^{*}$ \\
Triglycerides (mmol/L) & $2.69 \pm 1.87$ & $1.55 \pm 0.78$ & $0.000^{*}$ \\
HDL-C (mmol/L) & $1.07 \pm 0.30$ & $1.30 \pm 0.32$ & $0.000^{*}$ \\
Blood glucose (mmol/L) & $5.53 \pm 1.91$ & $4.72 \pm 0.99$ & $0.000^{*}$ \\
Blood pressure systolic (mm Hg) & $145.4 \pm 16.2$ & $137.8 \pm 18.0$ & $0.000^{*}$ \\
Blood pressure diastolic (mm Hg) & $86.5 \pm 8.1$ & $84.5 \pm 9.1$ & $0.015^{*}$ \\
\hline
\end{tabular}

$\mathrm{N}=$ sample size; $\mathrm{M}=$ Mean; $\mathrm{SD}=$ Standard deviation; $\mathrm{BMI}=$ Body mass index; WHR = Waist-to-hip ratio; HDL-C = High-density lipoprotein cholesterol; Significantly different at ${ }^{*} \mathrm{p}<0.05$.

Table 2. Metabolic syndrome and its components frequency in obese male and female.

\begin{tabular}{|c|c|c|c|c|}
\hline Variable & $\begin{array}{c}\text { Men }(\mathrm{N}=142) \\
\mathrm{n}(\%)\end{array}$ & $\begin{array}{c}\text { Women }(\mathrm{N}=185) \\
\mathrm{n}(\%)\end{array}$ & $\chi^{2}$ & $\mathrm{p}$ value \\
\hline Abdominal obesity & $122(85.9)$ & $170(91.9)$ & 2.41 & 0.120 \\
\hline Hypertriglyceridemia & $103(72.5)$ & $61(33.0)$ & 48.73 & $0.000^{*}$ \\
\hline $\begin{array}{l}\text { Lowered high-density } \\
\text { lipoprotein cholesterol }\end{array}$ & $74(52.1)$ & $99(53.5)$ & 0.02 & 0.888 \\
\hline Hyperglycemia & $34(23.9)$ & $14(7.6)$ & 15.92 & $0.000^{*}$ \\
\hline Hypertension & $101(71.1)$ & $111(60.0)$ & 3.89 & $0.049^{*}$ \\
\hline Metabolic syndrome & $96(67.6)$ & $87(47.0)$ & 12.98 & $0.000^{*}$ \\
\hline
\end{tabular}

glycemia and hypertension, MS prevalence in women was 1.44 times lower than that of men.

The ratios of the number of participants with lower or upper type of fat distribution in men and women were $28: 114$ and 84:101, respectively. Hence the frequency of lower type of fat distribution was $19.7 \%$ in men and $45.4 \%$ in women $(\mathrm{p}<0.000)$, which is logical because lower type of fat distribution is more associated with women. However, the frequency of lower type of fat distribution in men also proved to be rather high (approximately $20 \%$ ).

Table 3 presents the results of measuring the anthropometric and metabolic characteristics of the examined men and women with alimentary-constitutional obesity depending on whether they have lower or upper type of body fat distribution.
It was found that both men and women with lower type of fat distribution were younger than individuals of the same gender with upper type of fat distribution. Mean values of height, weight and body mass index of both men and women did not differ between groups with lower and upper types of fat distribution. Statistically significant differences were found in the values of waist circumference and WHR for individuals of the same gender with different types of fat distribution, and the rise of WHR value was due mainly to the increased waist circumference. The value of hip circumference at different types of fat deposition did not significantly change in both men and women.

The coefficients of variation for the index "waist circumference" in men with lower and upper types of fat distribution were $10.0 \%$ and $10.1 \%$, and those for the 
Table 3. Baseline characteristics of obese male and female with upper or lower types of body fat distribution.

\begin{tabular}{|c|c|c|c|c|c|c|c|c|}
\hline \multirow{4}{*}{ Variable } & \multicolumn{2}{|c|}{$\operatorname{Men}(N=142)$} & \multicolumn{2}{|c|}{ Women $(\mathrm{N}=185)$} & \multirow{2}{*}{\multicolumn{4}{|c|}{$\mathrm{p}$ value }} \\
\hline & Lower type & Upper type & Lower type & Upper type & & & & \\
\hline & & & & & & & & \\
\hline & 1 & 2 & 3 & 4 & $1-2$ & $3-4$ & $1-3$ & $2-4$ \\
\hline Age (years) & $38.9 \pm 11.3$ & $46.9 \pm 9.1$ & $40.7 \pm 11.4$ & $48.0 \pm 12.3$ & $0.000^{*}$ & $0.000^{*}$ & 0.483 & 0.448 \\
\hline Weight (kg) & $107.1 \pm 18.8$ & $111.7 \pm 19.9$ & $91.6 \pm 13.1$ & $95.9 \pm 18.2$ & 0.114 & 0.113 & $0.000^{*}$ & $0.000^{*}$ \\
\hline Height (cm) & $177.1 \pm 7.0$ & $177.2 \pm 6.0$ & $161.9 \pm 5.9$ & $161.8 \pm 6.3$ & 0.959 & 0.962 & $0.000^{*}$ & $0.000^{*}$ \\
\hline BMI & $34.2 \pm 5.8$ & $35.5 \pm 5.0$ & $35.0 \pm 5.2$ & $36.5 \pm 5.4$ & $0.013^{*}$ & $0.005^{*}$ & 0.109 & 0.097 \\
\hline Waist circumference $(\mathrm{cm})$ & $104.9 \pm 10.5$ & $115.3 \pm 11.6$ & $94.5 \pm 8.0$ & $105.5 \pm 10.1$ & $0.000^{*}$ & $0.000^{*}$ & $0.000^{*}$ & $0.000^{*}$ \\
\hline Hip circumference (cm) & $115.4 \pm 11.7$ & $113.2 \pm 9.7$ & $118.8 \pm 10.5$ & $117.1 \pm 10.9$ & 0.538 & 0.194 & $0.018^{*}$ & $0.002^{*}$ \\
\hline WHR & $0.91 \pm 0.03$ & $1.02 \pm 0.04$ & $0.80 \pm 0.04$ & $0.90 \pm 0.04$ & $0.000^{*}$ & $0.000^{*}$ & $0.000^{*}$ & $0.000^{*}$ \\
\hline Triglycerides (mmol/L) & $2.11 \pm 1.44$ & $2.83 \pm 1.93$ & $1.32 \pm 0.55$ & $1.75 \pm 0.88$ & $0.008^{*}$ & $0.000^{*}$ & $0.003^{*}$ & $0.000^{*}$ \\
\hline $\mathrm{HDL}-\mathrm{C}(\mathrm{mmol} / \mathrm{L})$ & $1.17 \pm 0.30$ & $1.04 \pm 0.29$ & $1.35 \pm 0.33$ & $1.26 \pm 0.30$ & $0.021^{*}$ & 0.089 & $0.018^{*}$ & $0.000^{*}$ \\
\hline Blood glucose $(\mathrm{mmol} / \mathrm{L})$ & $4.74 \pm 0.47$ & $5.73 \pm 2.07$ & $4.48 \pm 0.44$ & $4.92 \pm 1.25$ & $0.003^{*}$ & $0.009^{*}$ & $0.017^{*}$ & $0.000^{*}$ \\
\hline Blood pressure systolic (mm Hg) & $136.3 \pm 18.3$ & $147.7 \pm 14.8$ & $134.6 \pm 18.9$ & $140.4 \pm 16.9$ & $0.001^{*}$ & $0.017^{*}$ & 0.762 & $0.001^{*}$ \\
\hline Blood pressure diastolic $(\mathrm{mm} \mathrm{Hg})$ & $85.5 \pm 9.7$ & $86.8 \pm 7.7$ & $84.2 \pm 9.6$ & $84.7 \pm 8.8$ & 0.218 & 0.422 & 0.487 & $0.049^{*}$ \\
\hline
\end{tabular}

$\mathrm{N}=$ sample size; $\mathrm{n}=$ number of participants with upper or lower types of body fat distribution; $\mathrm{M}=\mathrm{Mean} ; \mathrm{SD}=\mathrm{Standard}$ deviation; $\mathrm{BMI}=\mathrm{Body}$ mass index; WHR $=$ Waist-to-hip ratio; HDL-C $=$ High-density lipoprotein cholesterol; Significantly different at ${ }^{*} \mathrm{p}<0.05$.

index "WHR" were $3.2 \%$ and $4.4 \%$, respectively. The coefficients of variation for the index "waist circumference" in women with upper and lower types of fat distribution were $8.4 \%$ and $9.6 \%$, and those for the index "WHR" were $5.0 \%$ and $4.8 \%$, respectively.

The blood triglyceride and glucose levels were higher and HDL-C levels were lower while systolic blood pressure was higher in both men and women with upper type of fat distribution than in participants with lower type of fat distribution. The blood triglyceride and glucose levels were lower and HDL-C levels were higher in women with both upper and lower types of fat distribution as compared to men with the same type of fat distribution, and systolic blood pressure was lower only at upper type of fat distribution in women as compared to men.

Table 4 presents the results of analyzing the frequency of metabolic syndrome and its individual components in both men and women depending on the type of body fat distribution. Men with lower type of body fat distribution as compared to upper type were characterized by a lower prevalence of abdominal obesity (1.9 times), hypertriglyceridemia (1.4 times), low HDL-C (1.6 times), and hypertension (2 times). Hyperglycemia was not observed in men with lower type of fat distribution. The frequency of metabolic syndrome in men with lower type of fat distribution was lower by 2.7 times than that of men with upper type of fat distribution.
A similar situation was observed in women. Women with lower type of fat distribution as compared to upper type had a lower prevalence of abdominal obesity (1.2 times), hypertriglyceridemia (1.8 times), low HDL-C (1.2-fold), and hypertension (in 1.5 times). Like in men, hyperglycemia was not observed in women with lower type of fat distribution. The frequency of metabolic syndrome in women with lower type of fat distribution was lower by 1.9 times than that of women with upper type of fat distribution.

\section{DISCUSSION}

There are no strict criteria to identify upper and lower types of fat distribution in men and women based on the WHR value. The boundary values of $0.90-1.00$ and 0.80 - 0.85 are used for men and women, respectively, above which upper type and below which lower type of fat distribution is identified. We used the boundary value of 0.95 for men and that of 0.85 for women; upper type of fat distribution was identified with a value equal or above it, and lower type of fat distribution was identified with a value below it. The prevalence of upper type of fat distribution in obese women was slightly higher than that of lower one. In obese men, the prevalence of upper type was much higher than that of lower type of fat distribution, but, nevertheless, the number of men with lower type of distribution constituted approximately $20 \%$. 
Table 4. Metabolic syndrome and its components frequency in obese male and female with upper or lower types of body fat distribution.

\begin{tabular}{|c|c|c|c|c|c|c|c|c|}
\hline \multirow[b]{2}{*}{ Variable } & \multicolumn{2}{|c|}{$\operatorname{Men}(N=142)$} & \multirow[b]{2}{*}{$\chi^{2}$} & \multirow[b]{2}{*}{$\mathrm{p}$ value } & \multicolumn{2}{|c|}{ Women $(\mathrm{N}=185)$} & \multirow[b]{2}{*}{$\chi^{2}$} & \multirow[b]{2}{*}{$\mathrm{p}$ value } \\
\hline & $\begin{array}{l}\text { Lower type } \\
(\mathrm{n}=28) \mathrm{n}(\%)\end{array}$ & $\begin{array}{c}\text { Upper type } \\
(\mathrm{n}=114) \mathrm{n}(\%)\end{array}$ & & & $\begin{array}{l}\text { Lower type } \\
(\mathrm{n}=84) \mathrm{n}(\%)\end{array}$ & $\begin{array}{c}\text { Upper type } \\
(\mathrm{n}=101) \mathrm{n}(\%)\end{array}$ & & \\
\hline Abdominal obesity & $14(50.0)$ & $108(94.7)$ & 33.57 & $0.000^{*}$ & $69(82.1)$ & $101(100)$ & 17.30 & $0.000^{*}$ \\
\hline Hypertriglyceridemia & $15(53.6)$ & $88(77.2)$ & 5.17 & $0.023^{*}$ & $19(22.6)$ & $42(41.6)$ & 6.63 & $0.010^{*}$ \\
\hline $\begin{array}{l}\text { Lowered high-density } \\
\text { lipoprotein cholesterol }\end{array}$ & $10(35.7)$ & $64(56.1)$ & 2.98 & 0.084 & $40(47.6)$ & $59(58.4)$ & 1.74 & 0.187 \\
\hline Hyperglycemia & 0 & $34(29.8)$ & 9.40 & $0.002^{*}$ & 0 & $14(13.9)$ & 10.69 & $0.001^{*}$ \\
\hline Hypertension & $11(39.3)$ & $90(78.9)$ & 15.34 & $0.000^{*}$ & $39(46.4)$ & $72(71.3)$ & 10.79 & $0.001^{*}$ \\
\hline Metabolic syndrome & $8(28.6)$ & $88(77.2)$ & 22.10 & $0.000^{*}$ & $27(32.1)$ & $61(60.4)$ & 13.57 & $0.001^{*}$ \\
\hline
\end{tabular}

$\mathrm{N}=$ Sample size; $\mathrm{n}=$ Number of participants in the presence of indication; $\chi^{2}=$ Criterion size; Significantly different at ${ }^{*} \mathrm{p}<0.05$.

The WHO report [38] showed that an increase in waist circumference and WHR is associated with increased disease risk, and this association is evident in diverse populations. Due to the relative ease of obtaining waist circumference, its use is favoured over waist-hip ratio. Waist circumference and WHR (as measures of abdominal obesity) were correlated with BMI, but the level of association varied, suggesting that these measures may provide different information and thus may not be interchangeable. Our results are consistent with this opinion.

It is difficult to divide the examined patients with obesity into groups based on the values of waist circumference because this characteristic is very variable, and the variability is not only ethnic or population [4], but also individual as indicated by our results on the coefficients of variation for the examined obese men and women. At the same time, WHR has a significantly smaller individual variability, and, most importantly, it allows us to distinguish obese male and female groups with low risk of atherosclerotic cardiovascular disease and type 2 diabetes mellitus. It should be noted that both men and women in the groups with lower type of fat distribution were missing such a component of metabolic syndrome as hyperglycemia i.e. they had the minimal risk of type 2 diabetes mellitus.

In [39] it was shown that that the simultaneous presence of an increased waist circumference combined with elevated fasting triglyceride concentrations (hypertriglyceridemic waist) could be used as a first screening phenotype to identify a subgroup of patients likely to be characterized by a cluster of features of the metabolic syndrome such as fasting hyperinsulinemia, elevated apolipoprotein $\mathrm{B}$ and in increased proportion of small LDL particles: the atherogenic metabolic triad. The examined obese men and women in the groups with upper type of body fat distribution had also significantly higher levels of serum triglycerides and a larger waist circumference than those with lower type of fat distribution. Therefore, the measurement of WHR may be a simpler and less expensive screening tool to identify individuals at risk of developing insulin resistance and metabolic syndrome in clinical practice.

The observed gender differences in the frequency of lower type of fat distribution between obese men and women may be associated with a larger amount of fat in the gluteofemoral area of women and a smaller amount of fat in the abdominal area of women as compared to men [40-42]. Differences in fat amount and topography, in turn, may be caused by different effects of female and male sex hormones on adipose tissue [43] and by genetic factors [44].

The accumulation of fat in abdominal region is connected with increase in size of intra-abdominal visceral adipose tissue, which is able to cause impaired glucose metabolism, lipid disorders and hypertension [29]. Visceral adipose tissue is a highly active endocrine organ and produces of so-called adipokines, which induce insulin resistance and play a major role in the pathogenesis of endothelial dysfunction and subsequent atherosclerosis $[28,30]$. At the same time plasma level of adiponectin, which protects against the development of diabetes mellitus, hypertension, inflammation and atherosclerotic vascular diseases, decreased in individuals with visceral fat accumulation. Hypoadiponectinemia caused by visceral fat accumulation might be one of the major causes of metabolic syndrome $[27,29]$. Therefore, visceral fat accumulation is a major correlate of a cluster of diabetogenic, atherogenic, prothrombotic and proinflammatory metabolic abnormalities referred to as the metabolic syndrome [32]. More expressed metabolic disorders in men and women with upper type of body fat distribution are connected just with visceral fat accumulation compared with lower type of fat distribution persons.

Waist circumference as well as WHR in men with up- 
per and lower types of fat distribution was greatly higher in comparison with women of according fat distribution. This allows us to say about the more visceral fat accumulation in men. One can be explained, that more metabolic disorders accumulation is connected just with larger visceral fat stocks in men compared with women independently from type of fat distribution. At the same time it is necessary to note, that blood pressure systolic both with diastolic one were increased in men compared with women of upper type of fat distribution. This fact also may be caused by larger visceral fat accumulation in men. However, it has been noted, that there is no gender difference of arterial pressure level in men and women with lower type of fat distribution. We can supposed, that the reason is relatively larger amount of subcutaneous fat in such men because it negatively correlates with atherogenic metabolic risk factors [30]. It was shown that an increased visceral adipose mass is clearly linked to insulin resistance syndrome and increased vascular risk, but the ratio of visceral to subcutaneous fat is a better correlate of insulin resistance. In this regard the utility of waist-to-hip ratio as a risk factor illustrates this principle and suggests that gynoid obesity may somehow be protective [45].

Fat depots from different areas of the body display distinct structural and functional properties and play disparate roles in pathology [46]. We have previously determined that in women with upper and lower types of fat distribution, changes in the values of indices characterizing the activity of carbohydrate and fat metabolism in stress tests such as oral glucose tolerance test and nutritional restriction test were multidirectional [47,48]. At the lower type of fat distribution, the preferential substrate of energy metabolism in obese women was glucose, and lipids were less involved in energy metabolism and accumulated in subcutaneous fat. At the upper type of fat distribution, free fatty acids became the preferential substrate for energy metabolism in obese women, which, in turn, contributed to the development of insulin resistance.

\section{CONCLUSION}

The carried out research showed that lower type of fat distribution can be identified by measuring the WHR value not only in women but also in men with obesity. Upper and lower types of fat distribution are associated with a varying risk of developing MS in both men and women with obesity. It should be noted that lower type of fat distribution in both gender persons also increases the risk of developing MS, although to a much lesser extent than upper type of fat distribution. This is due to the fact, that different types of fat distribution involve different pathogenetic mechanisms of obesity, which determine the risk of developing MS as well as cardiovascular diseases and type 2 diabetes mellitus that are associated with obesity.

\section{REFERENCES}

[1] Pan, W.H., Yeh, W.T. and Weng, L.C. (2008) Epidemiology of metabolic syndrome in Asia. Asia Pacific Journal of Clinical Nutrition, 17, 37-42.

[2] Taslim, S. and Tai, E.S. (2009) The relevance of the metabolic syndrome. Annals Academy of Medicine Singapore, 38, 29-35.

[3] Escobedo, J., Schargrodsky, H., Champagne, B., Silva, H., Boissonnet, C.P., Vinueza, R., Torres, M., Harnandez, R. and Wilson E. (2009) Prevalence of the metabolic syndrome in Latin America and its association with sub-clinical carotid atherosclerosis: The CARMELA cross sectional study. Cardiovascular Diabetology, 8, 52-60. doi:10.1186/1475-2840-8-52

[4] Alberti, K.G.M.M., Eckel, R.H., Grundy, S.M., Zimmet, P.Z., Cleeman, J.I., Donato, K.A., Fruchart, J.-Ch., James, W.P.T., Loria, C.M. and Smith, S.C. (2009) Harmonizing the metabolic syndrome: A joint interim statement of the International Diabetes Federation task force on epidemicology and prevention; National Heart, Lung and Blood Institute; American Heart Association; World Heart Federation; International Atherosclerosis Society; and International Association for the Study of Obesity. Circulation, 120, 1640-1645. doi:10.1161/CIRCULATIONAHA.109.192644

[5] Regitz-Zagrosek, V., Lehmkuhl, E. and Mahmoodzadeh, S. (2007) Gender aspects of the role of the metabolic syndrome as a risk factor for cardiovascular disease. Gender Medicine, 4, 162-177. doi:10.1016/S1550-8579(07)80056-8

[6] Xavier, N.P., Chaim, R.C., Gimeno, S.G., Ferreira, S.R., Hirai, A.T., Padovani, C.R., Okoshi, M.P. and Okoshi, K. (2010) Prevalence of metabolic syndrome in JapaneseBrazilians according to specific definitions for ethnicity. Metabolic Syndrome and Related Disorders, 8, 143-148. doi:10.1089/met.2009.0028

[7] Scholze, J., Alegria, E., Ferri, C., Langham, S., Stevens, W., Jeffries, D. and Uhl-Hochgraeber, K. (2010) Epidemiological and economic burden of metabolic syndrome and its consequences in patients with hypertension in Germany, Spain and Italy: A prevalence-based model. BMC Public Health, 10, 529. doi:10.1186/1471-2458-10-529

[8] Reaven, G.M. (2005) Insulin resistance, the insulin resistance syndrome, and cardiovascular disease. Panminerva Medica, 47, 201-210.

[9] Chan, J.C., Tong, P.C. and Critchley, J.A. (2002) The insulin resistance syndrome: mechanisms of clustering of cardiovascular risk. Seminars in Vascular Medicine, 2, 45-57. doi:10.1055/s-2002-23095

[10] Zimmet, P., Boyko, E.J., Collier, G.R. and de Courten, M. (1999) Etiology of the metabolic syndrome: Potential role of insulin resistance, leptin resistance and other players. Annals of the New York Academy of Sciences, 892, 25-44. 
doi:10.1111/j.1749-6632.1999.tb07783.x

[11] Zimmet, P., Magliano, D., Matsuzawa, Y., Alberti, G. and Shaw, J. (2005) The metabolic syndrome: A global public health problem and a new definition. Journal of Atherosclerosis and Thrombosis, 12, 295-300. doi:10.5551/jat.12.295

[12] Grundy, S.M., Cleeman, J.I., Daniels, S.R., Donato, K.A., Eckel, R.H., Franklin, B.A., Gardon, D.J., Krauss, R.M., Savage, P.J., Smith, S.C., Spertus, J.A. and Costa, F. (2005) Diagnosis and management of the metabolic syndrome: An American Heart Association/National Heart, Lung, and Blood Institute Scientific Statement. Circulation, 112, 2735-2752. doi:10.1161/CIRCULATIONAHA.105.169404

[13] Bener, A., Zirie, M., Musallam, M., Khader, Y.S. and Al-Hamaq, A.O. (2009) Prevalence of metabolic syndrome according to Adult Treatment Panel III and International Diabetes Federation criteria: A population-based study. Metabolic Syndrome and Related Disorders, 7, 221-229. doi:10.1089/met.2008.0077

[14] Assmann, G., Guerra, R., Fox, G., Cullen, P., Schulte, H., Willett, D. and Grundy, S.M. (2007) Harmonizing the definition of the metabolic syndrome: Comparison of the criteria of the Adult Treatment Panel III and the International Diabetes Federation in United States American and European populations. The American Journal of Cardiology, 99, 541-548. doi:10.1016/j.amjcard.2006.08.045

[15] Huang, P.L. (2009) A comprehensive definition for metabolic syndrome. Disease Models \& Mechanisms, 2, 231237. doi: $10.1242 / \mathrm{dmm} .001180$

[16] Akintunde, A.A., Ayodele, O.E., Akinwusi, P.O. and Opadijo, G.O. (2011) Metabolic syndrome: Comparison of occurrence using three definitions in hypertensive patients. Clinical Medicine \& Research, 9, 26-31. doi: $10.3121 / \mathrm{cmr} .2010 .902$

[17] Hartz, A.J., Rupley, D.C. and Rimm, A.A. (1984) The association of girth measurements with disease in 32,856 women. American Journal of Epidemiology, 1, 71-80.

[18] Svec, F., Rivera, M. and Huth, M. (1990) Correlation of waist to hips ratio to the prevalence of diabetes and hypertension in black females. Journal of the National Medical Association, 82, 257-261.

[19] Vague, J., Vague, Ph., Tramoni, M. and Vialettes, B. (1983) Clinical features of diabetogenic and atherogenic obesity. The Tohoku Journal of Experimental Medicine, 141, 147-159. doi:10.1620/tjem.141.Suppl_147

[20] Bjorntorp, P. (1987) Classification of obese patients and complications related to the distribution of surplus fat. The American Journal of Clinical Nutrition, 45, 112-125.

[21] Kissebah, A.H., Vydelingum, N., Murray, R., Evans, D.J., Hartz, A.J., Kalkhoff, R.K. and Adams, P.W. (1982) Relation of body fat distribution in metabolic complication of obesity. The Journal of Clinical Endocrinology \& Metabolism, 54, 254-260. doi:10.1210/jcem-54-2-254

[22] Bacha, F., Saad, R., Gungor, N., Janosky, J. and Arslanian, S.A. (2003) Obesity, Regional fat distribution, and syndrome $\mathrm{X}$ in obese black versus white adolescents: Race differential in diabetogenic and atherogenic risk factor.
The Journal of Clinical Endocrinology \& Metabolism, 88, 2534-2540. doi:10.1210/jc.2002-021267

[23] Singh, P., Somers, V.K., Rovero-Corral, A., Sert-Kuniyoshi, F.H., Pussalavidyasagar, S., Davison, D.E. and Jensen, M.D. (2012) Effects of weight gain and weight loss on regional fat distribution. The American Journal of Clinical Nutrition, 96, 229-233. doi:10.3945/ajen.111.033829

[24] Dalton, M., Cameron, A.J., Zimmet, P.Z., Shaw, J.E., Jolley, D., Dunstan, D.W. and Welborn, T.A. (2003) Waist circumference, waist-hip ratio and body mass index and their correlation with cardiovascular disease risk factors in Australian adults. Journal of Internal Medicine, 254, 555-563. doi:10.1111/j.1365-2796.2003.01229.x

[25] Elsayed, E.F., Tighiouart, H., Weiner, D.E., Griffith, J., Salem, D., Levey, A.S. and Sarnak, M.J. (2008) Waist-tohip ratio and body mass index as risk factors for cardiovascular events in CKD. American Journal of Kidney Diseases, 52, 49-57. doi:10.1053/j.ajkd.2008.04.002

[26] Zyriax, B.C., Schoeffauer, M., Klipstein-Grobusch, K., Boeing, H. and Windler, E. (2011) Differential association of anthropometric parameters with coronary risk in women-data of the CORS study. Obesity Facts, 4, 358364. doi:10.1159/000333964

[27] Matsuzawa, B.Y. (2010) Establishmen of a concept of visceral fat syndrome and discovery of adiponectin. Proceedings of the Japan Academy, Series B, Physical and Biological Sciences, 86, 131-141. doi:10.2183/pjab.86.131

[28] Gelsinger, C., Tschoner, A., Kaser, S. and Edenbichler, C.F. (2010) Adipokine update-New molecules, new functions. Wiener Medizinische Wochenschrift, 160, 377-390. doi:10.1007/s10354-010-0781-6

[29] Matsuzawa, Y. (2008) The role of fat topology in the risk of disease. International Journal of Obesity, 32, 83-92. doi:10.1038/ijo.2008.243

[30] Hamby, O., Porramatikul, S. and Al-Ozairi, E. (2006) Metabolic obesity: The paradox between visceral and subcutaneous fat. Current Diabetes Reviews, 2, 367-373. doi:10.2174/1573399810602040367

[31] Matsuzawa, Y., Funahashi, T. and Nakamura, T. (2011) The concept of metabolic syndrome: Contribution of visceral fat accumulation and its molecular mechanism. Journal of Atherosclerosis and Thrombosis, 18, 629-639. doi:10.5551/jat.7922

[32] Kishida, K., Funahashi, T., Matsuzawa, Y. and Shimomura, I. (2012) Visceral adiposity as a target for the management of the metabolic syndrome. Annals of Medicine, 44, 233-241. doi:10.3109/07853890.2011.564202

[33] Brochu, M., Tchernof, A., Dionne, I.J., Sites, C.K., Eltabbakh, G.H., Sima, E.A. and Poehlman, E.T. (2001) What are the physical characteristics associated with a normal metabolic profile despite a high level of obesity in postmenopausal women? The Journal of Clinical Endocrinology \& Metabolism, 86, 1020-1025. doi:10.1210/jc.86.3.1020

[34] Despres, J.-P., Arsenault, B.J., Cote, M., Cartier, A. and Lemieux, I. (2008) Abdominal obesity: The cholesterol of 
the 21 st century? Canadian Journal of Cardiology, 24, 712. doi:10.1016/S0828-282X(08)71043-2

[35] Astrakhantseva, E.L., Selyatitskaya, V.G., Melnikov, V.N., Shorin, Yu.P., Loginova, N.B. and Kuzminova, O.I. (2004) Endocrine and metabolic profile in obese women with different patterns of body fat distribution. Byullutin $S O$ $R A M N$, 1, 63-68.

[36] Krotkiewski, M., Bjorntorp, P., Sjostrom, L. and Smith, U. (1983) Impact of obesity on metabolism in men and women. The Journal of Clinical Investigation, 72, 11501162. doi:10.1172/JCI111040

[37] Pinchasov, B.B., Selyatitskaya, V.G. and Obuchov, I.V. (2011) Metabolic syndrome at women with different types of obesity. Bulletin of $N G U, \mathbf{9}, 36-43$.

[38] World Health Organization (2008) Waist Circumference and Waist-Hip Ratio. WHO Expert Consultation, Geneva, 8-11 December 2008.

[39] Lemieux, I., Poirier, P., Bergeron, J., Almeras, N., Lamarche, B., Cantin, B., Dagenais, G.D. and Despres, J.P. (2007) Hypertriglyceridemic waist: A useful screening phenotype in preventive cardiology? Canadian Journal of Cardiology, 23, 23-31. doi:10.1016/S0828-282X(07)71007-3

[40] Karastergiou, K., Smith, S.R., Greenberg, A.S. and Fried, S.K. (2012) Sex differences in human adipose tissuesThe biology of pear shape. Biology of Sex Differences, 3, 13.

[41] Demerath, E.W., Sun, S.S., Rogers, N., Lee, M., Reed, D., Choh, A.C., Couch, W., Czerwinski, S.A., Chumlea, W.C., Siervogel, R.M. and Towne, B. (2007) Anatomical patteming of visceral adipose tissue: race, sex, and age variation. Obesity (Silver Spring), 15, 2984-2993. doi:10.1038/oby.2007.356

[42] Goodpaster, B.H., Krishnaswami, S., Harris, T.B., Katsiaras, A., Kritchevsky, S.B., Simonsick, E.M., Nevitt, M., Holvoet, P. and Newman, A.B. (2005) Obesity, regional body fat distribution, and the metabolic syndrome in older men and women. Archives of Internal Medicine, 165, 777-783. doi:10.1001/archinte.165.7.777

[43] Elbers, J.M., Asscheman, H., Seidell, J.C. and Gooren, L.I. (1999) Effects of sex steroid hormones on regional fat depots as assessed by magnetic resonance imaging in transsexuals. American Journal of Physiology, 276, 317-325.

[44] Heid, I.M., Jackson, A.U., Randall, J.C., Winkler, T.W., Qi, L., Steinthorsdottir, V., Thorleifsson, G., Zillikens, M.C., Speliotes, E.K., Magi, R., Workalemahu, T., White, C.C., Bouatia-Naji, N., Harris, T.B., Bemodt, S.I., Ingelsson, E., Willer, C.I., Weedon, M.N., Luan, J., Vedantam, S., Esko, T., Kilpelainen, T.O., Kutalik, Z., Li, S., Monda, K.L., Dixon, A.L., Holmes, C.C., Kaplan, L.M., Liang, L., Min, J.L., et al. (2010) Meta-analysis identifies 13 new loci associated with waist-hip ratio and reveals sexual dimorphism in the genetic basis of fat distribution. Nature Genetics, 42, 949-960. doi:10.1038/ng.685

[45] McCarty, M.F. (2003) A paradox resolved: the postprandial model of insulin resistance explains why gynoid adiposity appears to be protective. Medical Hypotheses, 61, 173-176. doi:10.1016/S0306-9877(02)00238-4

[46] Wronska, A. and Kmiec, Z. (2012) Structural and biochemical characteristics of various white adipose tissue depots. Acta Physiologica, 205, 194-208. doi:10.1111/j.1748-1716.2012.02409.x

[47] Pinchasov, B.B., Selyatitskaya, V.G., Shorin, Y.P., Astrakhantseva, E.L. and Anufrienko, E.V. (2011) Women obesity type influence on glucose and insulin content in blood during oral glucose tolerance test dynamics. Fundamental Research, 9, 279-282.

[48] Pinchasov, B.B., Astrakhantseva, E.L. Shorin, Y.P., Kogay, M.A. and Selyatitskaya, V.G. (2009) Individual reactivity features of female organism with different type of obesity on nutrition deprivation. Bulletin of SO RAMN, 3, 110-114. 